\title{
Políticas educacionais e novas tecnologias: um desafio do século XXI.
}

\section{Educational policies and new technologies: a challenge of the XXI century}

\author{
Amábile Piacentine Drogui ${ }^{1}$; Vera Lúcia Lopes Cristovão²
}

\section{Resumo}

\begin{abstract}
Atualmente, há muitos recursos tecnológicos que possibilitam a interação e o desenvolvimento de processos de aprendizagem de línguas estrangeiras: ferramentas que podem ser utilizadas por professores e alunos na construção do conhecimento. Não é raro o discurso de que os professores precisam atualizarse, de que necessitam ir além da lousa e do giz e que se fazem necessários o letramento digital e a preparação para uma era tecnológica. Nosso objetivo, com esta pesquisa, é verificar que políticas educacionais estão sendo implementadas nas escolas nesse sentido, como se realiza a formação inicial e continuada dos professores de Línguas Estrangeiras (LE), para uso pedagógico das novas tecnologias, e que investimentos são feitos nos recursos didático-tecnológicos das escolas. Os estudos de Araújo (2007), Araújo e Dieb (2009), Marcuschi e Xavier (2010), Souza-Lima (2010) e Gomes (2012) formam o aporte teórico principal de nosso trabalho. Para a análise, coletamos, por meio de questionário, contribuições de professores de línguas estrangeiras de diferentes escolas públicas do Núcleo Regional de Ensino de Apucarana - PR. As vozes desses professores nos dão base para uma rica reflexão sobre as contradições existentes entre o que propõem as diretrizes curriculares e as condições oferecidas para cumpri-las.
\end{abstract}

Palavras chaves: Novas tecnologias. Políticas educacionais. Formação docente.

\begin{abstract}
Nowadays, there are many technological resources that make it possible the interaction and the development of the foreign languages learning processes. These tools can be used by teachers and students in the construction of knowledge. It is not unusual to hear that teachers need to update themselves, go further than the blackboard and the chalk, and that both digital literacy and preparation for the technological era have become necessary. This research aims to verify what educational policies have been developed, how it is carried out the education of pre-service and in-service teacher's of foreign language for the pedagogical use of new technologies, and what investments have been made in didactic and technological resources of schools. Araújo's (2007), Araújo and Dieb's (2009), Marcuschi and Xavier's (2010), Souza-Lima's (2010) and Gomes's studies are the main theoretical sources for this work. For the analysis, Data was collected by using a questionnaire from which the contribution of Foreign Language teachers of different public schools in the Regional Teaching Center of the city of Apucarana -Paraná was analysed. These teacher's voices have given us basis for a rich reflection about the contradictions that exist among the curricular guidelines and the conditions that are offered to accomplish them.
\end{abstract}

Keywords: New technologies. Educational policies. Teacher education.

\footnotetext{
${ }^{1}$ Graduada em Letras Português / Espanhol. Possui especialização em Língua Portuguesa e Línguas Estrangeiras. Atualmente é aluna do curso de Pós graduação em Estudos da Linguagem (PPGEL) da Universidade Estadual de Londrina. Email: mabiprof@ gmail.com

${ }^{2}$ Doutora em Linguística Aplicada e Estudos da Linguagem pela PUC-SP, professora associada da Universidade Estadual de Londrina (UEL), membro do Programa de Pós Graduação em Estudos da Linguagem (PPGEL) e líder do grupo de pesquisa Linguagem e Educação desde 2002. Email: veraluciacristovao@gmail.com
} 


\section{Introdução}

É inegável que, a partir da década de 70, a forma de comunicação humana sofreu significativas transformações. O telefone fixo, que era até então uma ferramenta altamente inovadora (ainda que permanente em nosso meio), tornou-se o passado da telefonia móvel. Esta, por sua vez, perdeu espaço para o que hoje consideramos a grande invenção: a internet.

A internet, que se tornou amplamente acessível a partir da década de 90, permitiu que, em fração de segundos, uma mensagem escrita percorresse quilômetros, e vem se tornando cada vez mais ágil e prática, pois já estamos caminhando para a web $3.0^{3}$. O surgimento da internet propiciou a evolução dos aparelhos para sua utilização: notebooks, netbooks, tablets, smartphones...

Aos poucos, a internet vai chegando a todos os lugares; o inimaginável se torna indispensável. Além de provocar constantes inovações tecnológicas, ela influencia a linguagem, a cultura, as maneiras de se ver e viver no mundo. Site, blog, facebook, e-mail, msn, chats, teleconferência, link e vários outros nomes passam a fazer parte de nosso cotidiano e necessitam ser estudados.

As inúmeras modificações nas formas e possibilidades de utilização da linguagem em geral e da língua são reflexos incontestáveis das mudanças tecnológicas emergentes no mundo, e de modo particularmente acelerado nos últimos 30 anos, quando os equipamentos informáticos e as novas tecnologias de comunicação começaram a fazer parte da vida das pessoas e das instituições. (MARCUSCHI; XAVIER, 2010, p. 11).

O ensino de línguas estrangeiras, por sua vez, não escapa destas inovações; os gêneros a serem abordados sofrem transformações e novos surgem. Ainda, é importante ensinar como escrever uma carta, mas não se pode negligenciar o e-mail. Interagir virtualmente, no contexto atual, não é menos relevante que fazê-lo frente a frente, "a
Internet gera novas formas de usar a linguagem, suscitando novos gêneros, inclusive inimagináveis até a sua criação.” (ARAÚJO, 2007, p. 15)

Para compreender e apropriar-se das novas formas de interação, são necessários novos materiais didáticos, o conhecimento de novas ferramentas e a preparação para seu uso. Por isso, nosso pensamento de que a escola deve ser o lugar de maior modernização, o mais atualizado ambiente social. Os profissionais da educação devem ter a oportunidade de constantemente construir novos conhecimentos sobre as transformações pelas quais passam os modos de interagir no mundo.

Comumente, lemos e ouvimos que os professores deveriam usar mais os recursos tecnológicos, para despertar o interesse dos alunos e prepará-los melhor para agir em um mundo cada vez mais globalizado. Nas Diretrizes Curriculares da Educação Básica de Língua Estrangeira Moderna (DCE/LEM) do estado do Paraná, consta que:

Além de descortinar os valores subjacentes no livro didático, recomenda-se que o professor utilize outros materiais disponíveis na escola: livros didáticos, dicionários, livros paradidáticos, vídeos, DVD, CDROM, Internet, TV multimídia, etc. (PARANÁ, 2008, p. 69).

Este documento político educacional parece informar que as escolas do estado possuem todos estes recursos e que cabe ao professor saber utilizálos corretamente. O olhar recai sobre o profissional do ensino, exigindo deste que se capacite e se adéque às mudanças que estão ocorrendo no contexto social de seus alunos.

Foi refletindo sobre estas pressuposições que tomamos a iniciativa de conhecer a opinião dos professores de Línguas Estrangeiras sobre o assunto. Com base em suas colocações, buscamos responder as duas questões que nortearam nossa pesquisa: Que políticas públicas estão sendo desenvolvidas para a inserção e uso de novas tecnologias nas escolas

\footnotetext{
${ }^{3}$ A Web 3.0 é a terceira geração da Internet. Esta nova geração prevê que os conteúdos online estarão organizados de forma semântica, muito mais personalizados para cada internauta, sites e aplicações inteligentes e publicidade baseada nas pesquisas e nos comportamentos. Esta nova Web também pode ser chamada de "A Web Inteligente". (SIGNIFICADO de... 2012).
} 
públicas? Que formação recebem os professores de línguas estrangeiras para uso das novas tecnologias em suas aulas?

Para coletar os dados, desenvolvemos um questionário com sete questões que foram respondidas por dez professores de Línguas Estrangeiras de escolas pertencentes ao núcleo regional de Apucarana - PR. Estas questões permitiram que os participantes comentassem sobre os equipamentos, para uso das novas tecnologias de suas escolas, a formação inicial e continuada que tiveram (ou não) para trabalhar com eles e sobre o uso destes em suas aulas.

As vozes desses professores formam o corpus de análise deste artigo. Tentaremos construir uma relação entre às políticas públicas e os subsídios que se oferecem às escolas e aos profissionais do ensino. Nosso objetivo é colocar em pauta fatores que envolvem os processos de ensino e que vão além da sala de aula e do educador. Também, almejamos contribuir, mesmo que de maneira modesta, para uma reflexão sobre as atuais políticas públicas, no que se refere ao uso das novas tecnologias nas escolas do Paraná.

\section{Novas Tecnologias, Políticas Públicas e Ensino}

Para quem a língua e a linguagem são objetos de ensino, parece não ser uma opção incluir os gêneros digitais em seus planejamentos, o não fazê-lo resulta em uma aprendizagem claudicante e obsoleta. Tanto para os que trabalham com língua materna quanto com línguas estrangeiras, se há mudanças nas formas de comunicação, há mudanças nas ferramentas de ensino.

Araújo (2007, p. 15) argumenta que o interesse de diferentes pesquisadores pela Internet "se justifica porque a Internet gera novas formas de usar a linguagem, suscitando novos gêneros, inclusive inimagináveis até sua criação.” Marcuschi (2010, p. 16) explica que o fato da nova tecnologia reunir, em um único espaço, a escrita, a imagem e a sonoridade, interfere na natureza dos recursos linguísticos e justifica parte do seu sucesso.

Tomando como base as definições de linguagem e língua defendidas por Garcez (1998), podemos afirmar que as novas formas de linguagem geradas pela Internet são modificações observáveis, parte destas transformações adquire um caráter duradouro e passa a ser componente da língua.

[...] a linguagem é uma atividade humana cujas categorias observáveis se modificam no tempo e apresentam um funcionamento profundamente interdependente do tipo de contexto social em que ocorrem. [...] língua é produto de um trabalho coletivo e histórico, de uma experiência que se multiplica de forma contínua e duradoura, assegurando intrinsecamente uma margem de flexibilidade $\mathrm{e}$ indeterminação. (GARCEZ, 1998, p. 46-47)

As novas formas de linguagem do contexto digital, no qual nos vemos inseridos, precisam fazer sentido, pois, como afirma Coscarelli (2009), já fazem parte de nós:

Vivemos o digital, somos o digital, fazemos o digital. Isso faz parte de nós, cidadãos inseridos no mundo contemporâneo, e se não faz, ainda, deveria fazer, ou vai fazer logo. (COSCARELLI, 2009, p. 13)

$\mathrm{O}$ acesso à internet, possível por meio do computador e do celular, considerando suas diferentes versões e nomes, é de conhecimento da maioria das pessoas; pouquíssimos lugares desconhecem totalmente esse recurso. Este fato, no entanto, não implica em saber usá-lo eficazmente como ferramenta de comunicação. Faz-se necessário o letramento digital, entendido por Carvalho (2009, p. 84) como

[...] não somente o conhecimento tecnológico da informática, mas também, e principalmente, os usos que se faz desses recursos informáticos de maneira significativa, entendendo suas práticas e possibilidades em situações sociais e reais do dia a dia dos internautas.

A autora, que pesquisa sobre o professor de espanhol e as práticas do idioma na $W e b$, defende que o uso do computador pode servir tanto como recurso didático quanto como ferramenta de "integração e interação entre nativos e aprendizes da língua meta." (CARVALHO, 2009, p. 84). Aprender na escola se torna um caminho para continuar evoluindo fora dela. 
Se a Internet gera novas formas de linguagem, e é este o objeto de ensino de professores de línguas estrangeiras, como conceber escolas sem este recurso ou com acesso tão precário a ele?

Falar, portanto, do ensino de línguas estrangeiras, sem fazer menção ao uso da Internet, dos diversos letramentos da Web demandados por tantos gêneros emergentes, como recursos pedagógicos, é algo, a nosso ver, fora de cogitação, uma vez que estas ferramentas já fazem parte do cotidiano de nossos alunos. (CARVALHO, 2009, p. 85)

Voltamos a salientar que a escola deveria ser o espaço de maior acesso às novas tecnologias, pois, como defende a maioria dos discursos políticos, a escola prepara para o exercício da cidadania. Sabemos que não serão as novas tecnologias que irão resolver o problema do ensino, há questões ideológicas muito mais abrangentes que afetam a educação. $\mathrm{O}$ que desejamos com esta pesquisa é ampliar o olhar sobre as possibilidades de uso das novas tecnologias na escola e refletir sobre as necessidades de atualizar este espaço de tamanha relevância social.

Só é possível uma escola pública bem equipada e com profissionais bem preparados, se existirem políticas públicas que contemplem essas ações.

Entendemos por políticas públicas as medidas que o Estado, enquanto poder constituído, toma para a obtenção de resultados específicos nas diversas áreas em que atua. No caso do uso das novas tecnologias para o ensino de línguas, tomamos como base as DCE/ LEM do Paraná, documento que orienta a prática do professor e precisa ser coerente com o meio para o qual se destina. Como já mencionado na introdução deste artigo, as DCE/LEM (PARANÁ, 2008) vigentes em nosso estado parecem afirmar que estão disponíveis nas escolas os recursos digitais necessários, para que os professores os utilizem em suas aulas, e prevê que estes estão preparados para tal prática.

Ao tratar os conteúdos de Língua Estrangeira Moderna, o professor proporcionará ao aluno, pertencente a uma determinada cultura, o contato e a interação com outras línguas e culturas. Desse encontro, espera-se que possa surgir a consciência do lugar que se ocupa no mundo, extrapolando o domínio linguístico. (PARANÁ, 2008, p. 69).

O próximo capítulo tem por objetivo trazer a voz dos docentes e avaliar a relação teoria e prática, no que se refere a documentos e ações governamentais na busca por melhorias na educação.

\section{Um Olhar Docente sobre a Inserção e o Uso das Novas Tecnologias nas Escolas Públicas}

Com a ajuda da coordenadora do Centro de Línguas Estrangeiras Modernas (CELEM) da cidade de Apucarana, enviamos, por email, aos professores de Línguas Estrangeiras, pertencentes ao Núcleo Regional da Educação deste município, um questionário contendo sete questões, das quais, seis serviram como corpus para esta pesquisa e uma se somará aos dados de outro artigo que estamos produzindo.

Dez professores responderam, nove do sexo feminino e um do masculino. Sete atuam na área de Língua Espanhola e três em Língua Inglesa ${ }^{4}$. Apenas dois lecionam em uma mesma escola, ou seja, temos comentários e opiniões sobre nove diferentes estabelecimentos.

Para identificar os participantes, preservando seus nomes, utilizamos uma sigla composta pela letra $\mathrm{P}$ - Professor, LE- Língua Espanhola ou LI - Língua Inglesa + um número de identificação. Ex: PLE1. Enumeramos de 1 a 10, de acordo com a ordem de chegada do questionário respondido por e-mail.

As questões propunham avaliar os equipamentos disponíveis em suas escolas, a formação que receberam para utilizá-los e a importância destes em suas aulas. Na sequência, tentaremos analisar as respostas 5 , fazendo um comparativo com o que se espera da prática docente em relação ao uso das novas tecnologias nas escolas públicas do Paraná.

\footnotetext{
${ }^{4}$ Observamos que sete dos dez participantes atuam, também, em outras áreas: Língua Portuguesa, Pedagogia, Artes, Literatura, Gestão e Sala Multifuncional.

${ }^{5}$ Informamos que não faremos qualquer tipo de alteração nos textos dos participantes, o objetivo é extrair o conteúdo, o que cada um deseja enunciar ao ter a oportunidade de expor sua opinião.
} 


\section{Os Equipamentos Tecnológicos das Escolas e as Orientações das DCE/LEM}

A primeira questão solicita ao professor que opine, justificando, se sua escola está ou não adequada tecnologicamente. Nove dos participantes responderam que não e, apesar de a maioria pertencer a escolas diferentes, os argumentos foram bastante próximos.

O quadro 1, a seguir, apresenta alguns dos argumentos dados pelos participantes, ao afirmarem que a escola não está adequada tecnologicamente.

Quadro 1 - Argumentos dos participantes, ao afirmarem que a escola onde lecionam não está adequada tecnologicamente.

\begin{tabular}{|c|c|}
\hline $\begin{array}{l}\text { Identificação do } \\
\text { participante }\end{array}$ & Argumento \\
\hline PLE1 & $\begin{array}{l}\text { “...primeiro porque não atende a demanda e depois necessitamos da ajuda de } \\
\text { alguém para instalar, falta fio, tomadas, isso quando estão em bom estado." }\end{array}$ \\
\hline PLE2 & "...os computadores e as TVS Pendrive estão todos quebrados." \\
\hline PLE3 & $\begin{array}{l}\text { "...em minha escola necessita de mais equipamentos, pois pelo número de } \\
\text { alunos quando trabalhado falta." }\end{array}$ \\
\hline PLI5 & $\begin{array}{l}\text { “... A tecnologia é a competência dos profissionais da educação que atuam } \\
\text { com a força e a dedicação com mínimo de atenção dos governadores que, nem } \\
\text { imaginam a que duras sobrevive uma escola..." }\end{array}$ \\
\hline PLE6 & $\begin{array}{l}\text { "...ainda estamos muito atrasados, visto que ainda temos que preencher os } \\
\text { livros de chamada de modo bastante arcaico, e nem sempre podemos contar } \\
\text { com a tecnologia funcionando adequadamente..." }\end{array}$ \\
\hline PLI7 & $\begin{array}{l}\text { "A TV pen drive não supre todas as necessidades tecnológicas e as escolas } \\
\text { quando tem, tem apenas um DATA SHOW para vários professores, e os } \\
\text { computadores de hoje quando chegam, já estão ultrapassados...( }\end{array}$ \\
\hline PLE8 & $\begin{array}{l}\text { "Não, os equipamentos não funcionam ou funcionam mal, poucos aparelhos } \\
\text { para muitos alunos..." }\end{array}$ \\
\hline PLI9 & $\begin{array}{l}\text { "...não temos laboratório de informática, temos apenas } 3 \text { tvs sendo apenas } 1 \\
\text { pen drive e } 2 \text { dvds para atender todas as turmas." }\end{array}$ \\
\hline PLE10 & "...há falta de técnico que nos auxilie..." \\
\hline
\end{tabular}

Fonte: As autoras

O quadro 2 apresenta o argumento dado pelo tecnologicamente: participante que considerou sua escola adequada 
Quadro 2 - Argumento do participante, ao afirmar que a escola onde leciona está adequada tecnologicamente.

\begin{tabular}{|l|l|}
\hline $\begin{array}{l}\text { Identificação do } \\
\text { participante }\end{array}$ & Argumento \\
\hline PLE5 & "em relação a tempos anteriores diria que sim, pois temos a TV pen drive, rádio." \\
\hline
\end{tabular}

Fonte: As autoras

Temos consciência de que, se observarmos o Brasil como um todo, o estado do Paraná está entre os que possuem escolas em boas condições. Este fato, no entanto, não exclui necessidades de melhorias, as vozes dos docentes parecem indicar que o caminho a percorrer para o uso das novas tecnologias, com objetivos didáticos, está ainda em seu início.

As quarta, quinta e sexta questões de nosso questionário, também, propiciam comentários sobre o estado de funcionamento dos equipamentos disponíveis na escola, o uso durante as aulas e a existência de projetos que envolvam sua utilização. As respostas foram muito parecidas com as da primeira questão, a participante PLE1 menciona um esforço individual para aquisição de aparelhos e, ao mesmo tempo, ressalta que essa não é uma possibilidade para todos: "fiz um consórcio e comprei caixa de som, data show e netbook. Mas sabemos que nem todos os profissionais conseguem fazer isso."

Entre os gêneros textuais que as DCE/LEM do Paraná propõem que o professor utilize, estão os da esfera midiática:

Quadro 3 - Esferas midiáticas

\begin{tabular}{|ll|}
\hline Blog & Reality Show \\
Chat & Talk Show \\
Desenho Animado & Telejornal \\
E-mail & Telenovelas \\
Entrevista & Torpedos \\
Filmes & Vídeo Clip \\
Fotoblog & Vídeo Conferência \\
Home Page & \\
\hline
\end{tabular}

Fonte: Paraná (2008, p. 86).
Alguns livros didáticos já trazem exemplos destes gêneros, contudo, pensando na visão de língua e linguagem que as DCE/LEM defendem, uma abordagem eficaz exige uma maior aproximação do contexto social de produção de cada gênero, ou seja, analisar um blog descrito em um livro didático é bem diferente de uma interação em um computador com acesso à internet. Saber o que é um chat é bem diferente de poder usá-lo para interagir em LE com alguém em outro país.

[...] a proposta adotada nestas Diretrizes se baseia na corrente sociológica e nas teorias do Círculo de Bakhtin, que concebem a língua como discurso. [...] a língua concebida como discurso, não como estrutura ou código a ser decifrado, constrói significados e não apenas os transmite. O sentido da linguagem está no contexto de interação verbal e não no sistema linguístico. (PARANÁ, 2008, p. 58, grifo nosso)

Para colocar em prática as orientações das DCE/LEM, no que se refere aos gêneros digitais, é necessário que a escola realmente possua os recursos descritos, que estes estejam em bom estado e que se oferte qualificação para seu uso. O bem elaborado discurso sobre o ensino de LE precisa vir acompanhado por subsídios e formação para sua prática; são necessárias políticas públicas que vão além da produção de um documento. Araújo (2007) argumenta fortemente nesse sentido, afirmando que

[...] o governo brasileiro deve saber que oportunizar aos estudantes e aos professores da Educação Básica experiências de interação e aprendizagem em ambiente internetiano não se faz jogando nas escolas máquinas jurássicas que, ao invés de seduzir seus usuários, devem chateá-los com sua lentidão [...]. Além disso, para que a escola entre cada vez mais nesse campo, é preciso cobrar políticas públicas mais sérias de formação docente às secretarias de educação, políticas essas que deem conta das especificidades da inserção da informática na escola. (ARAÚJO, 2007, p. 17, grifo nosso) 
A fraca estrutura nas escolas e as dificuldades encontradas para utilização dos recursos não indicam, todavia, que nada está sendo feito, parece haver um desejo de evoluir, no que se refere ao uso das novas tecnologias e dos gêneros digitais no ensino de LE. A participante PLI5 relata: "as turmas de $8^{\circ}$ s anos têm um blog que usamos para que realizem atividades de fixação de modo lúdico, postam suas opiniões(...) e, a PLI6, afirma: "os alunos em geral sentem maior facilidade para entender, acredito que seja devido à visualização”.

Os demais participantes afirmam tentar utilizar as ferramentas disponíveis em suas aulas. A maioria das respostas é bastante semelhante:

- $\quad$ Quando é possível sua utilização eles são de grande valia como instrumentos complementares ao ensino, gerando muito interesse nos alunos(PLE1).

- $\quad$ Falta tempo para conhece-los, mas quando tenho tempo manuseio para meu conhecimento e posteriormente repassar ao meus alunos. (PLE3).

- prefiro organizar em casa onde a internet é mais rápida e liberada para que eu possa elaborar atividades que precisam ser adaptadas pra a TV Pen Drive (PLI7).

O que a participante PLI7 relata, revela que, além de não ter boa qualidade de sinal de Internet em sua escola, faz-se necessário adaptar as atividades para a TV multimídia, tornando ainda mais moroso o processo de preparação das aulas. A televisão instalada nas escolas públicas paranaenses não é um aparelho que esteja disponibilizado em outros ambientes, como o notebook e o data show, por exemplo; ela possui formatação própria, lendo apenas arquivos salvos em extensões específicas. Todo ano, ingressam novos professores na rede pública, é possível prever que, no primeiro ano de trabalho, muitos não façam uso da TV multimídia e do laboratório de informática, com Linux instalado em suas máquinas, por desconheceram seus modos de funcionamento.

Apenas uma das escolas tem um projeto envolvendo o uso dos equipamentos disponíveis e, segundo a participante, destina-se apenas aos alunos: "Para os professores não. O único projeto que envolve tecnologia na escola é para os alunos." (PLE3). Enviamos e-mail para a professora perguntando-lhe como é este projeto e se abrange todos os alunos, ela respondeu: "é o Projeto Mais Educação, onde eles têm aulas de Informática."

Verificando como funciona este programa federal, Mais Educação ${ }^{6}$, constatamos que a escola contrata livremente os profissionais que irão trabalhar nos projetos previamente selecionados. Não há necessidade de formação documentada na área, são chamados de monitores. As atividades são optativas para os alunos e ocorrem no contraturno.

De acordo com o Ministério de Educação e Cultura - MEC,

[...] o Programa Mais Educação, criado pela Portaria Interministerial $n^{\circ}$ 17/2007, aumenta a oferta educativa nas escolas públicas por meio de atividades optativas que foram agrupadas em macrocampos como acompanhamento pedagógico, meio ambiente, esporte e lazer, direitos humanos, cultura e artes, cultura digital, prevenção e promoção da saúde, educomunicação, educação científica e educação econômica. (BRASIL, 2012)

É no macrocampo "cultura digital" que a escola pode inserir as aulas de informática que, por sua vez, ocorrem de acordo com a estrutura disponível.

Ainda que não seja o objetivo deste artigo avaliar este ou outro programa específico, pareceu-nos adequado fazer essa pausa para observá-lo, já que foi mencionado por uma de nossas participantes.

A leitura imediata que fazemos, e nem por isso menos consciente, é a de que o governo prevê que, apenas enviando uma verba e alguns kits de instrumentos, o resultado esperado será alcançado. A direção da escola que, até então, não realizou uma ação como esta e nem recebeu curso de como fazê-lo, terá que se responsabilizar por "fazer dar certo" o programa federal. Mendes et al. (2010, p.4) enfatizam que

\footnotetext{
${ }_{6}$ Mais informações no portal do MEC: http://portal.mec.gov.br/index.php?Itemid=86\&id=12372\&option=com content\&view=article
} 
[...] as políticas públicas se materializam por intermédio da ação concreta de sujeitos sociais e de atividades institucionais que as realizam em cada contexto e condicionam os resultados. Por isso, 0 acompanhamento dos processos pelos quais são implementadas, além da avaliação de seu impacto sobre a situação existente, devem ser permanentes.

\section{A Formação Docente e o Uso das Novas Tecnologias}

A segunda questão que propusemos aos participantes lhes permitia escrever sobre a preparação que receberam para uso das novas tecnologias em sua formação inicial.

Ainda que quatro participarmos tenham concluído a graduação em 2002, um em 2001 e um em 2010, todos informaram que não receberam preparação, para uso das novas tecnologias no ensino, durante sua formação inicial. O quadro a seguir apresenta alguns comentários referentes a esta questão.

Quadro 4 - Comentários dos participantes sobre sua (não) preparação, durante a formação inicial, para uso das novas tecnologias no ensino.

\begin{tabular}{|c|c|}
\hline $\begin{array}{l}\text { Identificação do } \\
\text { participante }\end{array}$ & Argumento \\
\hline PLE1 & "víamos quando tinha alguns cursos, mas aprendizado e treinamento não." \\
\hline PLE2 & $\begin{array}{l}\text { "Não tive preparação. A minha turma foi a primeira turma de Espanhol da } \\
\text { faculdade, eles estavam iniciando o curso." }\end{array}$ \\
\hline PLE3 & "Em nenhuma de minhas graduações recebi formação..." \\
\hline PLI4 & "Não. O que sei aprendi e aprendo por vontade própria e interesse." \\
\hline PLE5 & $\begin{array}{l}\text { “... quanto a utilização de tecnologias estou aprendendo buscando cursos e } \\
\text { sozinha." }\end{array}$ \\
\hline PLI6 & “...naquele tempo sequer sonhávamos com toda essa tecnologia." \\
\hline PLI7 & "...aprendemos apenas usar quadro, giz e quando muito, um aparelho toca CD." \\
\hline PLE8 & $\begin{array}{l}\text { "Não tive nenhuma preparação em minha graduação para utilização das } \\
\text { novas tecnologias. Os professores também não se encontravam preparados para } \\
\text { utilizá-las e as aulas eram dadas tradicionalmente..." }\end{array}$ \\
\hline PLE9 & "Na época de minha formação tudo isso era um pouco novidade ainda." \\
\hline PLE10 & $\begin{array}{l}\text { "Havia na faculdade um laboratório de línguas, mas tivemos acesso ao mesmo } \\
\text { umas } 3 \text { ou } 4 \text { vezes e só isso." }\end{array}$ \\
\hline
\end{tabular}

Fonte: As autoras

Por este quadro, é possível ter uma amostra de como a formação inicial, tanto pelo rápido avanço que teve a tecnologia no campo do ensino nos últimos anos "Naquele tempo sequer sonhávamos com toda esta tecnologia.", quanto pelo atraso das universidades "Os professores também não se encontravam preparados para utilizá-las e as aulas eram dadas tradicionalmente", não tem 
dado conta de preparar os professores para o uso das novas tecnologias; evidenciando não somente a necessidade de um melhor preparo durante a formação inicial como a de uma formação continuada de qualidade, que alcance tanto os professores que concluíram há muitos anos sua graduação quanto os recém-formados.
A terceira questão solicita aos participantes que avaliem a capacitação que recebem, do estado do Paraná, em sua formação continuada, para uso das tecnologias disponíveis na escola. Sete dos participantes afirmam não ter participado de qualquer curso do Estado nessa área para poder avaliar.

Quadro 5 - Comentários dos participantes sobre sua (não) preparação, durante a formação continuada, para uso das novas tecnologias disponíveis na escola.

\begin{tabular}{|c|c|}
\hline $\begin{array}{l}\text { Identificação do } \\
\text { participante }\end{array}$ & Argumento \\
\hline PLE1 & $\begin{array}{l}\text { "Não recebemos nenhum treinamento, quando queremos e temos um horário } \\
\text { "livre", pesquisamos na internet ou pedimos ajuda para os outros." }\end{array}$ \\
\hline PLE2 & $\begin{array}{l}\text { "Não. Tem cursos disponiveis, mas só que são em outras cidades, e você tem } \\
\text { que arcar com as despesas, sair da sua cidade, é muito difícil." }\end{array}$ \\
\hline PLE3 & $\begin{array}{l}\text { "Estou atuando no estado desde o ano passado, mas eu não participei de } \\
\text { nenhum curso que me capacite para o uso das novas tecnologias." }\end{array}$ \\
\hline PLI4 & "Não. O que sei aprendi e aprendo por vontade própria e interesse." \\
\hline PLI7 & “...aprendemos apenas usar quadro, giz e quando muito, um aparelho toca CD." \\
\hline PLE8 & $\begin{array}{l}\text { "O Estado até oferece, mas sempre em horário normal de aulas o que dificulta a } \\
\text { realização desses cursos por nós professores que temos uma jornada de } 40 \text { horas } \\
\text { semanais." }\end{array}$ \\
\hline PLE9 & "Não." \\
\hline PLE10 & $\begin{array}{l}\text { "Nunca tive oportunidade, por trabalhar em mais de uma escola, os horários } \\
\text { nunca me oportunizam." }\end{array}$ \\
\hline
\end{tabular}

Fonte: As autoras

Percebemos que a questão de compatibilidade de horários (e também de localidade) merece ser repensada por parte dos organizadores de cursos destinados aos professores. Não basta constar que o governo está oferecendo cursos de capacitação, se o acesso a estes não for viabilizado.
Duas professoras conseguiram participar de algum momento de capacitação e avaliaram de forma positiva. O quadro a seguir traz seus comentários. 
Quadro 6 - Comentários dos participantes sobre sua preparação, durante a formação continuada, para uso das novas tecnologias disponíveis na escola.

\begin{tabular}{|l|l|}
\hline $\begin{array}{l}\text { Identificação do } \\
\text { participante }\end{array}$ & Argumento \\
\hline PLE5 & "recebi um curso de capacitação para manusear o computador, avalio como bom." \\
\hline PLI6 & $\begin{array}{l}\text { "Sim, acredito que os que estão realmente interessados conseguem aprender a usar a } \\
\text { tecnologia disponivel na escola." }\end{array}$ \\
\hline
\end{tabular}

Fonte: As autoras

Um dos participantes não mencionou ter realizado ou não algum curso ofertado pelo Estado, apenas comentou que há cursos em horários que nem sempre são compatíveis: "constantemente é oferecido um curso ou outro sobre novas tecnologias, mas nem sempre temos horário compativel com o curso." (PLI7). Reforçamos a necessidade de viabilizar o acesso aos cursos ofertados.

Como pudemos constatar, nestas duas questões sobre formação, $100 \%$ dos participantes informam não ter recebido preparação para uso das novas tecnologias em sua formação inicial e apenas $20 \%$ relatam ter participado, em sua formação continuada, de algum curso, oferecido pelo estado do Paraná, com esta finalidade. Além de não existirem equipamentos modernos nas escolas, não há capacitação para utilizar os já disponibilizados pelo Estado.

Buscar atualizar-se é uma recomendação para qualquer profissional, não rejeitamos aqui a ideia de que os docentes estejam inclusos nesse rol. Porém, não podemos deixar de mencionar que o surgimento de novos equipamentos em um ambiente de trabalho requer, conjuntamente, investimento nos recursos humanos. Uma empresa que não deseja estar ultrapassada investe em tecnologia e na capacitação de seus profissionais. A escola, a nosso ver, deveria funcionar da mesma forma: investir em aparelhos de última geração e em formação de alto nível. Reis (2009) ressalta que a escola é uma instituição de difusão de saberes e, como tal, "não pode caminhar à margem da evolução tecnológica nem ignorar as transformações ocorridas na sociedade." (REIS, 2009, p. 100).

Saber usar o computador, a Internet, a TV, o DVD e outros recursos tecnológicos, como ferramentas didático-pedagógicas, exige capacitação, preparo e projetos coletivos. Gomes (2008) chama atenção para o fato de que há um grande número de professores que não ainda não sabem utilizar o computador como recurso didático:

[...] ao observamos o uso do computador na atividade profissional pelo professor, por exemplo, é comum percebermos que dentre aqueles poucos que têm o equipamento à disposição em seu ambiente de trabalho, ainda é grande o número de pessoas que preferem deixá-lo de fora de suas atividades por não saberem utilizá-lo como recurso didático ou por não enxergarem propósitos práticos para o seu uso em sala de aula, apesar de familiarizados com ele em outros ambientes, como o doméstico, por exemplo. (GOMES, 2008, p. 5)

\section{Considerações Finais}

Apesar de haver, no estado do Paraná, um documento que orienta o trabalho docente, as vozes dos professores revelam que há muito mais envolvido do que o desejo e a consciência do profissional da necessidade de inovar suas ferramentas. As respostas de nossos participantes não nos parecem denunciar que estão confortáveis ou acomodados, o que encontramos foi um grupo que se sente despreparado e diante de recursos desmotivadores. 
Nosso estudo, infelizmente, não nos levou a conclusões muito distintas do que foi já relatado por Aragão (2009), ao publicar sua pesquisa sobre o uso das novas tecnologias no ensino de inglês no estado da Bahia; o autor afirma que, devido à precariedade dos recursos e o despreparo docente, "não é difícil ver o professor de inglês circunscrito ao uso da lousa, do giz e da escrita como únicas tecnologias educacionais.”(ARAGÃO, 2009, p. 62).

Anosso ver, precisamos, como educadores, cobrar ações públicas, no que se refere à modernização de nossas escolas e à eficácia da formação inicial e continuada. Sentir-se preparado para uso das novas tecnologias em sala de aula certamente influenciará a autoestima do professor e auxiliará na motivação dos alunos para a aprendizagem.

As políticas públicas educacionais, nesse âmbito, muitas vezes, resumem-se a programas de incentivo ao uso das novas tecnologias, premiando professores e escolas que, isoladamente, conseguem realizar algum brilhante projeto. Essas práticas parecem querer provar que depende unicamente dos profissionais da educação, "se um fez, todos podem fazer". Parabenizar um bom projeto pode ser uma maneira de ocultar a negligência do Estado em cumprir o dever de criar, ele próprio, um programa coletivo, que envolva a todos, que ofereça materiais e preparação dignos para poder cobrar mudanças positivas na maneira de ensinar. Biancheti (2001), ao criticar atitudes de distanciamento e imparcialidade do Estado, afirma que "o neoliberalismo rechaça qualquer ação estatal que vá além de ser um árbitro imparcial das disputas." (BIANCHETI, 2001, p.88).

Não negamos a existência de educadores preguiçosos ou poucos engajados com os processos de ensino, entretanto, até para estes deve existir políticas públicas de fiscalização e acompanhamento. Culpar o professor pelo insucesso de determinadas ações não é o caminho para melhorar a educação.

O desafio de superar a defasagem tecnológica, que marca a escola em nossos dias, precisa ser encarado e aceito por todos: governantes, secretarias de educação, núcleos regionais, docentes, alunos e familiares. É preciso envolver-se, cobrar e fiscalizar o que vem sendo feito e o que se deve fazer para tornar a escola um ambiente à frente de seu tempo, em condições reais de auxiliar o indivíduo em sua construção como sujeito participativo das transformações sociais.

\section{Referências}

ARAGÃO, Rodrigo Camargo. Projeto forte: formação, reflexão e tecnologias no ensino na Bahia. In: ARAÚJO, Julio Cesar; DIEB, Messias. (Org.). Letramentos na web: gêneros, interação e ensino. Fortaleza: UFC, 2009. p. 58-81.

ARAÚJO, Julio Cesar. Internet e ensino: novos gêneros, outros desafios. Rio de Janeiro: Lucerna, 2007.

BIANCHETTI, Roberto Gerardo. Modelo neoliberal e políticas educacionais. 3. ed. São Paulo: Cortez, 2001.

BRASIL. Ministério da Educação. Programa mais educação. Disponível em: <http://portal.mec.gov. br/index.php?Itemid=86\&id=12372\&option=com content\&view $=$ article/>. Acesso em: 4 abr. 2012.

CARVALHO, Tatiana Lourenço. O professor de espanhol diante dos letramentos da Web e a utilização dos gêneros digitais. In: ARAÚJO, Julio Cesar; DIEB, Messias. (Org.). Letramentos na web: gêneros, interação e ensino. Fortaleza: UFC, 2009. p. 82-98.

COSCARELLI, Carla Viana. Linkando as ideias dos textos. In: ARAÚJO, Julio Cesar; DIEB, Messias. (Org.). Letramentos na web: gêneros, interação e ensino. Fortaleza: UFC, 2009. p. 13-20.

GARCEZ, Lucilia Helena do Carmo. A escrita e o outro: os modos de participação na construção do texto. Brasília: UnB, 1998.

GOMES, Francisco Wellington Borges. Linguagem e tecnologia: desafios para o ensino de línguas na sociedade da informação. Revista Litteris, Rio de Janeiro, ano 1, 2008. Disponível em: $<$ http://revistaliter.dominiotemporario.com/ doc/LinguagemFrancisco.pdf $>$. Acesso em: 6 abr. 2012. 
MARCUSCHI, Luiz Antonio. Gêneros textuais emergentes no contexto da tecnologia digital. In: MARCUSCHI, Luiz Antonio; XAVIER, Antonio Carlos. (Org.). Hipertexto e gêneros digitais: novas formas de construção do sentido. 3. ed. Rio de Janeiro: Lucerna, 2010. p. 15-80.

MARCUSCHI, Luiz Antonio; XAVIER, Antonio Carlos. (Org.). Hipertexto e gêneros digitais: novas formas de construção do sentido. 3. ed. Rio de Janeiro: Lucerna, 2010.

MENDES, Ana Maria Coelho Pereira.; SOUZALIMA, José Edmilson; HAMMERSCHMIDT, Karina Silveira de Almeida.; LOURENÇO, Marcus Santos.; GUARAGNI, Marcus Vinicius. Políticas públicas, desenvolvimento e as transformações do Estado brasileiro. In: SILVA, Christian Luiz da; SOUZA-LIMA, José Edmilson. (Org.). Politicas públicas e indicadores para o desenvolvimento sustentável. São Paulo: Saraiva, 2010. p. 3-34.

PARANÁ. Secretaria de Estado da Educação. Superintendência de Educação. Diretrizes curriculares de língua estrangeira moderna para a educação básica. Curitiba, 2008.

REIS, Francisca das Chagas S. O e-mail e o blog: interação e possibilidades pedagógicas. In: ARAÚJO, Julio Cesar; DIEB, Messias. (Org.). Letramentos na web: gêneros, interação e ensino. Fortaleza: UFC, 2009. p. 111-121.

SIGNIFICADO de Web 3.0. Significado.com.br. Disponível em: $<$ http://www.significados.com.br/ web-3-0/>. Acesso em: 8 abr. 2012. 